\title{
Erratum to: Beyond Acclamations and Excuses: Environmental Performance, Voluntary Environmental Disclosure and the Role of Visibility
}

\author{
Cedric E. Dawkins \\ John W. Fraas
}

\begin{abstract}
Some researchers have argued that firms with favorable environmental performance are more likely to provide voluntary environmental disclosure, while others have argued that firms with poor environmental performance are most likely to disclose. The authors propose a curvilinear relation between environmental performance and environmental disclosure that is moderated by visibility. Data were obtained from S\&P 500 firms queried by Ceres' Climate Disclosure Project. Results show a U-shaped environmental performance-environmental disclosure relation and a main effect for visibility but no moderating effect for visibility on the U-shaped environmental performance-environmental disclosure relation. The authors discussed the implications of these results for future research and practice.
\end{abstract}

KEY WORDS: corporate social responsibility, disclosure, environmental disclosure, corporate social responsibility disclosure, voluntary environmental disclosure

The online version of the original article can be found under doi:10.1007/s10551-009-0149-2.

The Editor-in-Chief and Springer wish to inform readers of this journal that the retraction of the paper by Cedric Dawkins and John W. Fraas entitled "Beyond acclamations and excuses: Environmental performance, voluntary environmental disclosure and the role of visibility" published in Online First under the DOI number 10.1007/s10551-009-01492 has been replaced by a correction. The Dawkins/Fraas paper is largely the work of Dawkins and Fraas, but includes some sentences and ideas that previously appeared in an unpublished paper and/or Power Point presentation with the same title only with Cedric Dawkins and Cynthia Clark Williams listed as authors. The earlier collaborative work with Professor Williams should have been acknowledged.
Environmental disclosure is growing in importance due to the increased demand for environmental performance information and the prospect that such information will improve financial performance (Al-Tuwaijri et al., 2004; Porter and van der Linde, 1995). There are wide variations in environmental disclosure across companies (Kolk, 2003; Patten, 2002; Russo and Fouts, 1997) and differing views on why companies voluntarily provide environmental disclosure. Voluntary disclosure includes information that is not required by law or code of practice (e.g., annual reports and proxy statements) or goes beyond what is required, and is useful for stakeholder decision-making. Essentially, there are two linear explanations for voluntary disclosure that are termed as legitimacy theory and voluntary disclosure theory.

Voluntary disclosure theory (Dye, 2001; Verrecchia, 1983) is a strategy-based approach that predicts a positive association between environmental performance and the level of voluntary environmental disclosure. According to voluntary disclosure theory, superior environmental performers will attempt to distinguish themselves by disclosing information acclaiming their favorable performance relative to their peers. Firms with inferior environmental records will disclose less in an attempt to avoid negative exposure. Conversely, the legitimacy theory approach (e.g., Patten, 2002) posits that voluntary disclosure is a function of pressure by institutional and public stakeholders. Because disclosure is essentially a reaction to this pressure, firms with less favorable environmental performance records use disclosure to explain their performance. Essentially, the voluntary disclosure approach focuses on acclamations of good 
performance, while the legitimacy approach is directed toward excusing poor performance.

In order to move research on environmental disclosure beyond acclamations and excuses, we propose a curvilinear relationship between environmental performance and environmental disclosure that is moderated by visibility. If such a curvilinear relationship exists, it provides a means with which to reconcile the two primary explanations for corporate disclosure. In what follows we will review and assess the current research on environmental performance and disclosure, develop hypotheses about the proposed relationships, and present and discuss the results of hypothesis testing.

\section{Environmental performance and voluntary environmental disclosure}

Although there has been an increase in the number of firms providing environmental information (Kolk, 2003), previous research on the environmental performance-environmental disclosure relation has yielded mixed results. Several recent studies have concluded that heightened attention to environmental performance results in more pressure on poor performing firms to increase disclosure. Patten (2002) opined that previous studies of voluntary disclosure were inconclusive because of methodological shortcomings such as small sample sizes, narrow environmental performance measures, and lack of adequate control measures for firm size and industry. He addressed those shortcomings using Toxic Release Index ${ }^{1}$ (TRI) data to measure environmental performance, a widely dispersed sample of 131 US firms, and the Wiseman (1982) Index, which focuses on the financial consequences of environmental activities, for content analysis, and found a negative relationship between environmental performance and environmental disclosure.

Hughes et al. (2001) examined the relationship between environmental disclosures and environmental performance using annual report statements as a proxy for disclosure, a version of the Wiseman Index (1982) to measure environmental disclosures and environmental performance ratings derived from the Council of Economic Priorities (CEP). They found no significant difference in environmental disclosures between companies rated "good" and companies rated "average" in environmental performance, but firms receiving poor environmental performance ratings provided more environmental disclosure. Cho et al. (2006) focused on the content of disclosure among firms with different levels of environmental performance by differentiating between monetary and non-monetary environmental disclosure. Given that quantitative data are more precise, they assumed that worse environmental performers would make more non-monetary environmental disclosures than their better performing competitors. Worse environmental performers did, in fact, make higher levels of non-monetary environmental disclosures than their better performing counterparts. Thus, in each of the preceding studies, there was a negative relationship between environmental performance and disclosure, which is consistent with the legitimacy-based approach to disclosure.

Leading environmental performers have a favorable story to tell and their behavior can be more fully explained by a strategy-based approach like voluntary disclosure theory. Al-Tuwaijri et al. (2004) examined environmental disclosure based on content analysis of SEC filings and $10 \mathrm{~K}$ forms, and environmental performance based on TRI estimates of total recycled waste. They determined that strong environmental performance was significantly associated with environmental disclosures and economic performance. Finally, Clarkson et al. (2008) assessed the relationship between environmental performance and environmental disclosure using content analysis of sustainability reports of 191 firms in five high-polluting industries in the U.S. The relationship between TRI and sales and the percentage of recycled waste were used as proxies for environmental performance. They found a positive relationship between environmental performance and the level of voluntary disclosures. Consequently, they discounted the impact of legitimacy theory in predicting the level of disclosure.

In sum, the mixed results are attributable to methodological issues that will be addressed later and the seemingly incompatible theoretical foci of the studies. Nevertheless, the legitimacy-based and voluntary disclosure approaches are fundamentally similar in that they seek to favorable manage disclosure, but do so from different operational conditions - one focused on maintaining legitimacy and the other on strategic position. It may be that the 
legitimacy and strategy-based approaches to environmental disclosure need not be mutually exclusive. Clarkson et al. (2008) allude to this by concluding that legitimacy theory is useful in predicting what is disclosed, but inaccurate in predicting how much is disclosed. Thus, the theoretical divide between legitimacy-based and voluntary disclosure-based approaches to environmental disclosure may be over ought.

\section{Hypothesis}

\section{Environmental performance and voluntary disclosure}

Legitimacy theory best explains the level of disclosure provided by firms that utilize communication strategies to protect legitimacy in the face of sociopolitical challenges. There are a number of reasons why poor environmental performers comply with requests for voluntary disclosure. First, disclosure of environmental activity is a potential source of legitimacy (Hooghiemstra, 2000) and because legitimacy substantially enhances firm performance (Oliver, 1991), it is likely that poor performing firms will attempt to capitalize on that benefit. When firms meet environmental expectations they are perceived to be higher in legitimacy (Bansal and Clelland, 2004). On the other hand, firms failing to meet environmental expectations are perceived to be of lower environmental legitimacy but can mitigate the negative effects by disclosing information and expressing commitment to the environment (Brown and Deegan, 1998). For example, Deegan et al. (2000) determined that the extent of corporate environmental disclosure was positively associated with environmental lobby groups' concerns about environmental performance, and following environmental catastrophes, companies operating in the affected industries increased their annual report disclosure.

Second, the marginal utility of enhanced legitimacy may be even greater for poor performing firms than for firms with better environmental records. Poor performers can do nothing, which would tend to increase attention and the likelihood of external regulation (Dutton and Ashford, 1993; Mahon and Waddock, 1992; Wartick and Cochran, 1985), improve their performance, or influence the way their performance is perceived by stakeholders. Ignoring performance may exacerbate the problem and improving performance may take considerable time. Gray et al. (1995) and Lindblom (1994) argue that companies whose social legitimacy is threatened have incentives to increase environmental disclosures to: (a) educate and inform relevant publics about changes in their performance, (b) change perceptions about their performance, (c) deflect attention from the issue of concern by highlighting other accomplishments, and (d) seek to change public expectations of their performance. Clearly, the most egregious performers will encounter problems by denying requests for disclosure. Ceres, an organization of environmentally conscious investors, accompanied the release of its 2006 Climate Risk Disclosure Project report with the following headline on its blog, S\&P 500 Companies Faulted for Poor Climate Disclosure (Ceres, 2007a). One month later Ceres released a list of climate watch firms from several industries ${ }^{2}$ and investors filed shareholder resolutions with those firms (Ceres, 2007b). Providing disclosure in these circumstances can decrease the length of the issue's life cycle. Thus, influencing stakeholder perception through disclosure is a suitable way to manage poor environmental performance.

Conversely, the voluntary disclosure literature (Verrecchia, 1983) posits that good environmental performers have a number of reasons to inform stakeholders of their environmental activities. First, companies may want to call greater attention to improvements made to environmental programs and capture the implicit endorsement of key stakeholders in the process. Responsiveness to CSR issues, such as environmental impact, can lead to competitive advantage if a company is able to focus stakeholders' attention on that resource (Mackey et al., 2007). Because environmental performance can help a firm build its brand and reputation (Fombrun, 1996; McWilliams and Siegel, 2001; Waddock and Graves, 1997) and lead to above-average industry profits (Russo and Fouts, 1997), it is important to adopt a pattern of disclosure that capitalizes on this asset.

Another benefit of this approach is that stakeholders are able to receive "bad news" from the company along with good news. Godfrey (2005) proposes that, because stakeholders have become more wary about the motives of various aspects of CSR, it is important for companies to avoid the appearance of ingratiation or symbolic legitimacy (e.g., Adams, 2004; Bansal and Kistruck, 2006; Hughes et al., 2001). It may be that companies that have 
adopted a full disclosure posture with respect to disclosure have done so because they fundamentally believe that their strengths outweigh their weaknesses and are committed to environmental disclosure as a matter of values. Also, these companies may want to call greater attention to the program and policy improvements they have made to their environmental programs and capture the implicit endorsement of key stakeholders like Ceres or KLD. Being perceived as legitimate improves access to needed resources (Pfeffer and Salancik, 1978). Voluntary disclosure theory predicts a positive association between environmental performance and the level of voluntary environmental disclosure.

Thus, poor environmental performance can lead to an expectations gap, which is a difference between the way a firm performs and how key external stakeholders believe it should perform (Wartick and Mahon, 1994). Firms with unfavorable environmental performance provide disclosure to manage this expectations gap. On the other hand, firms that are exceeding stakeholder expectation provide disclosure to highlight their favorable performance, but not so much disclosure as to invite additional media scrutiny. If both, voluntary disclosure and legitimacy theory, rationales for disclosure are accurate then as performance increases or decreases disclosure should also increase. Firms with average environmental performance have little to gain by highlighting this fact and are less likely to raise the ire of stakeholders by withholding disclosure because they are meeting the basic performance expectations. As illustrated in Figure 1, the varying objectives of firms lead to a curvilinear relationship between environmental performance and environmental disclosure. We expect the following:

Hypothesis 1: A U-shaped relationship exists between environmental performance and voluntary environmental disclosure.

The role of visibility

If both approaches to disclosure are valid, as previous studies seem to indicate, then there may be additional factors common to both low and high performing firms, such as visibility. According to Pfeffer and Salancik (1978), visibility affects the level of outside pressure a firm experiences because stakeholders take greater interest in firms that are visible. Meznar et al. (2006) found that press coverage was positively associated with firms' attempts to shape the way outsiders perceived the firm and/or the issue. Stakeholders' demands for compliance create institutional pressures (Maignan and Ferrell, 2001), and the media exacerbate these pressures by focusing public attention on corporate behavior (Chen and Meindl, 1991; Erfle et al., 1990). As press exposure increases so does public scrutiny of the firm in question, and this leads to corporate adjustments designed to placate stakeholders.

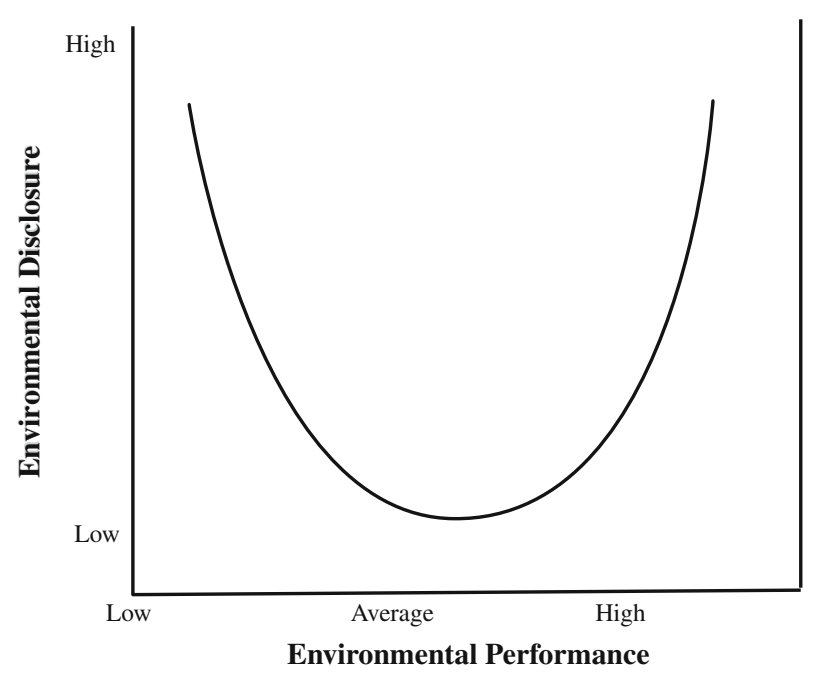

Figure 1. Curvilinear relationship between environmental performance and environmental disclosure. 
Arguably, increased visibility through press coverage is most likely in the case of inadequate performance than of favorable performance (Gans, 1979). Even so, the expectation gap is likely to be demonstrated more dramatically by comparing poor performers with their peer institutions to illustrate how an issue should be addressed. Bansal and Roth (2000) have even suggested that some environmentally legitimate firms are reluctant to tout their environmentally responsible activities and stop disclosure after they achieve legitimacy to avoid the additional visibility and the attending scrutiny. Low performing firms are not meeting stakeholder expectations, which bring increased scrutiny on their shortcomings (Klein, 2000). For example, reporting on environmental mishaps increased environmental disclosures in the affected industries (Deegan and Gordon, 1996; Deegan et al., 2000).

It is important to note that visibility need not be directly related to environmental issues. Highly visible firms that do well or poorly with respect to environmental issues would tend to receive more media scrutiny for environmental performance because of their visibility. Following this line of reasoning, firms with neither low nor high levels of environmental performance are less visible and thereby better positioned strategically to withhold disclosure than either their lower or higher performing peers. It appears that as environmental performance decreases or increases, firms are more vulnerable to the effects of visibility and thereby more likely provide disclosure. That is, the effects of environmental performance [ep] on environmental disclosure [ed] depend on the degree of visibility on the firm in question [v], such that firm's visibility will generally increase disclosure over what would be expected if there was no visibility (e.g., $\mathrm{ed}=\mathrm{ep} \star \mathrm{v})$.

Hypothesis 2: Visibility moderates the U-shaped relationship between environmental performance and voluntary environmental disclosure.

\section{Methods}

Sample

The firms in this study were members of the S\&P 500 , a stock market index containing the stocks of
500 large capitalization corporations from the United States. We have also employed the 2005 Kinder, Lydenberg and Domini (KLD) ratings of environmental performance and the 2006 Ceres Carbon Disclosure Project survey of S\&P 500 firms (Ceres, 2007a). KLD is a ratings firm specializing in corporate social performance (CSP) analysis and rankings. The advantages of the KLD ratings are that they (a) utilize an objective set of evaluative criteria (b) are consistently applied across companies by a specialized, independent staff, (c) employ a wide variety of company, government, NGO, and media sources, and (d) have been widely used in CSP research (e.g., Dawkins, 2002; Johnson and Greening, 1999; Johnston, 1994; Waddock, 2003). Ceres is a network of investors, environmental groups, and public interest groups that encourages firms to incorporate environmental and social challenges into their daily decision-making and has launched programs such as the Global Reporting Initiative, the Sustainable Governance Forum on Climate Risk, and the Investor Network on Climate Risk.

Firms were included in the study sample if they were (a) included in the S\&P 500 in 2005 and 2006, (b) evaluated for environmental performance in the 2005 KLD performance ratings; and (c) received a request from Ceres to participate in the Ceres 2006 Climate Disclosure Project survey. Our hypotheses imply a temporal relationship between variables in that environmental performance and visibility would influence later disclosure. Thus, we have staggered the years of data collection to allow the KLD environmental performance ratings and visibility to influence later levels of environmental disclosure. This procedure yielded 363 firms that ranged in total assets $^{3}$ from $\$ 259.0$ to $\$ 1,051,450$ million. The mean number of employees for the sample firms was 43,400 and the mean return on assets was $8.28 \%$.

\section{Measures}

As noted earlier, the mixed results in studies of environmental performance and disclosure are partly attributable to continuing methodological difficulties that result in limited industry coverage and small sample sizes, and failure to adequately reconcile the legitimacy theory and voluntary disclosure approaches. Because the Wiseman scale (e.g., 
Clarkson et al., 2008; Patten, 2002) focuses on the financial consequences of corporate environmental activities, poor environmental performers disclose more because they have greater exposure and must detail the financial ramifications of those exposures in their regulatory filings. A number of the studies continue to use the CEP ratings that monitor a limited number of firms and industries resulting in restricted sample size and breadth. In addition, the CEP evaluates environmental performance in different industries with different criteria, which limits generalizability.

Also, a number of studies used the TRI measure for environmental performance that focuses on negative outcome measures (e.g., Al-Tuwaijri et al., 2004; Patten, 2002) to the virtual exclusion of input measures such as equipment maintenance, the use of recyclables in production, and ISO 14,000 environmental certification. As will be detailed later, we address these shortcomings using (a) an environmental performance measure that includes both input and outcome measures, (b) the S\&P 500 sample to improve sample size and industry representation, and (c) the Ceres disclosure ratings to assess disclosure rather than the Wiseman scale.

Consequently, the key research design challenge in the study of environmental performance and disclosure was to develop reliable proxies for the variables. Besides increasing the number and variety of firms in the sample, we have addressed this challenge in two ways. First, we employed a measure of environmental performance that included positive input activities as well as the more commonly employed negative outcome metrics, which enabled us to compare the disclosure practices of good performers and poor performers concurrently. Second, we used an environmental disclosure measure developed by Ceres that avoided the negative bias of the Wiseman scale and the use of different industry performance measures that called into question the validity of cross-industry comparisons.

\section{Dependent variable}

Voluntary environmental disclosure comprised the firms' responses to an environmental disclosure survey request made by Ceres. In response to the survey, Ceres categorized firm responses into four areas: (a) ignored or refused the request, (b) provided alternative information, (c) provided information but required that it not be made public, ${ }^{4}$ or (d) complied with the request. Because ignoring the request and refusing the request have the same outcome, we placed these four responses into three basic areas: (a) no disclosure, firms that ignored or refused the request; (b) partial disclosure, firms provided different ${ }^{5}$ or incomplete information; or (c) full disclosure, complied with the request by providing complete information. In this way, the dependent variable voluntary environmental disclosure was developed as an ordinal variable with three levels: no disclosure $(n=139)$, partial disclosure $(n=89)$, and full disclosure $(n=127)$.

\section{Independent variables}

The independent variable environmental performance was determined on the basis of KLD environmental performance ratings. To evaluate environmental performance, KLD evaluated a number of activities that were indicators of environmental strengths or environmental concerns. Those questions are listed in the Appendix. The KLD environmental performance strength assessment considered proactive measures of performance such as pollution prevention programs, use of recycled materials in manufacturing, maintenance of equipment, and ISO certifications. Conversely, the environmental weakness assessment accounted for negative outcomes such as recently paid fines for waste management violations, high toxic emissions, and regulatory fines or controversies. A strength or weakness on an assessment item was indicated numerically with a rating of 1 . If the firm did not exhibit the strength nor weakness item in question, this was indicated with a rating of 0 (KLD Analytics, 2007b). Environmental performance was developed as a continuous variable by subtracting the pro-rata concern score from the pro-rata strength score for each firm. ${ }^{6}$

A second independent variable was formed from the values in the environmental performance variable. Each of the environmental performance values was squared to construct the variable required to reflect the second-degree component of the U-shaped relationship between environmental performance and voluntary environmental disclosure stipulated in Hypothesis 1. This independent variable was labeled environmental performance ${ }^{2}$.

The third independent variable was visibility. As with other measures of visibility (e.g., Dawkins, 2005; Meznar and Nigh, 1995), we used the number 
and timing of articles published in the popular press to measure visibility. The newspapers selected had national reputations and were from different regions of the U.S. to assure broad coverage. The number of times a firm was mentioned in the New York Times, Washington Post, Wall Street Journal, USA Today, or Los Angeles Times during the calendar year of 1996 were identified by a Lexis-Nexis search for the sample firms and summed to yield a visibility score. ${ }^{7}$ Altogether, the firms in our sample were mentioned in 11,258 articles during 1996 with scores ranging from 0 to 678 . The visibility variable had very positively skewed distributions, and thus we used logarithmic transformation to permit valid statistical analyses.

Two additional independent variables were generated to determine whether the U-shaped relationship between environmental performance and voluntary environmental was modified by visibility. The first of these variables, which was labeled enperXvis, was formed by multiplying the environmental performance variable by the visibility variable. The second variable, which was labeled enperXvis ${ }^{2}$, was constructed by multiplying the square of each environmental performance value by the company's visibility value.

\section{Control variables}

Previous research has indicated that performance, size, and industry can affect disclosure practices and CSP ratings (Bushman et al., 2004; Graves and Waddock, 1994; Patten, 2002; Roberts, 1992). Hence, we formed additional independent variables as control variables. Financial performance was measured as the return on assets, and size was measured as the logarithm of total assets. ${ }^{8}$ Industry was employed as a control variable because pollution propensity and outside monitoring varied from industry to industry. Our sample included firms from the 10 industry sectors used in the Ceres Risk Disclosure Survey (Ceres, 2007c). The highest concentrations of firms were in consumer discretionary (68) and finance (60) industries, while telecommunications industry sectors had the lowest concentration of firms (7). Each of the industry classifications was well represented as a percentage of total sample size except telecommunications, which comprised $1.9 \%$ of the sample. Summary data on the industry and disclosure variables from the sample firms are provided in Table I.
TABLE I

Disclosure and industry frequencies

\begin{tabular}{lrr}
\hline & $N$ & Percentage \\
\hline Ceres & & \\
No disclosure & 139 & 39.4 \\
Partial disclosure & 89 & 24.8 \\
Full disclosure & 127 & 35.8 \\
Industry & & \\
Consumer discretionary & 66 & 18.6 \\
Consumer staples & 30 & 8.5 \\
Energy & 23 & 6.5 \\
Finance & 60 & 16.9 \\
Healthcare & 36 & 10.1 \\
Industrial & 42 & 11.8 \\
Information technology & 51 & 14.4 \\
Materials & 19 & 5.4 \\
Telecommunications & 7 & 2.0 \\
Utilities & 21 & 5.9
\end{tabular}

Data analysis

Construction of the ordinal regression model

The dependent variable, voluntary disclosure, consisted of three categories: (a) no disclosure, firms that ignored or refused the request; (b) partial disclosure, firms provided different ${ }^{9}$ or incomplete information; or (c) full disclosure, complied with the request by providing complete information. In the analysis conducted for this study, these three categories of the voluntary disclosure dependent variable were treated as ordinal under the assumption that the categories have a natural ordering (none, partial, and full), but the distances between adjacent levels are unknown. Due to this assumption, the data were subjected to ordinal regression analyses to statistically test the two hypotheses previously presented. The first ordinal regression model, labeled Model 1, which was used to test the Hypothesis 1, included the continuous independent variables of environmental performance, environmental performance ${ }^{2}$, and visibility. In addition, Model 1 included the continuous control variables of size and financial performance, and 9 of the 10 dichotomous variables representing the 10 industries. The second ordinal regression model, labeled Model 2, which was used to test the Hypothesis 2, included the same 
independent and control variables as those used in Model 1. Model 2, however, also included the enperXvis and the enperXvis ${ }^{2}$ independent variables.

Before conducting the analysis of the two ordinal regression models, a decision had to be made regarding which link function (i.e., the transformation of the cumulative probabilities that allows estimation of the model) to choose. Because the proportions of companies for the three categories of the outcome variable are not extremely dissimilar (i.e., no disclosure, 0.39; partial disclosure, 0.25; and full disclosure, 0.36), a logit function was selected to serve as the link function. It should be noted that because the two extreme groups (i.e., no disclosure and full disclosure) had the highest proportion of companies a Cauchit function could have been selected as the link function. The analysis of the ordinal regression models that used the Cauchit, however, produced results that were very similar to the results produced by the two ordinal regression models that used the logit function. The results reported are based on the ordinal regression models that used a logit link functions.

\section{Results}

Analysis of the ordinal regression models

Table II contains the estimated ordinal logistic regression models used to test the two hypotheses. However, before these results could be used to test those hypotheses, it was necessary to determine whether the estimated parameters are the same for all categories of the dependent variable using a test of parallelism (Table III).

The test of parallelism is conducted by estimating a model that assumes parallelism (i.e., the parameters of the independent and control variables are the same across the three dependent variable categories) and a model that does not assume parallelism. We can assume parallelism if the model that requires the parameter estimates to be the same (i.e., the Null Model) is not significantly improved by the model that does not assume parallelism (i.e., the General Model). Parallelism can be assumed if difference between the two $-2 \log$-likelihood values of the models is not statistically significant, as determined by a $\chi^{2}$ test. The $-2 \log$-likelihood values of the
Null Model and the General Model were 705.99 and 694.91, respectively, for Model 1. The difference between these two values was not statistically significant $\left(\chi^{2}(14)=11.09, p=0.68\right)$. Thus, the assumption of parallelism is plausible for Model 1 . For Model 2, the -2 log-likelihood values of the Null Model and the General Model were 703.93 and 692.17, respectively. The difference between these two values was not statistically significant $\left(\chi^{2}\right.$ $(16)=11.76, p=0.76)$. Thus, the assumption of parallelism is also plausible for Model 2.

The overall model fit for each of the two ordinal regression models was assessed through the statistical test of the difference between the -2 log-likelihood values of a Null Model, which required each of the coefficients of the independent and control variables to equal 0, and a General Model, which allowed the coefficients to differ from 0 . With respect to Model 1 , the $-2 \log$-likelihood values of the Null Model and the General Model were 768.02 and 705.99, respectively. The difference between these two values was statistically significant $\left(\chi^{2}(14)=62.03\right.$, $p<0.001)$. In regards to Model 2, the -2 loglikelihood values of the Null Model and the General Model were 768.02 and 703.93, respectively. The difference between these two values was statistically significant $\left(\chi^{2}(16)=64.09, p<0.001\right)$. Thus, the ordinal regression models used in this study provide an improvement over the baseline intercept-only model, which indicates the model provides better predictions than one would obtain by just guessing based on the marginal probabilities for the outcome categories.

\section{Test of Hypothesis 1 with Model 1}

To determine if the relationship between environmental performance and environmental disclosure was U-shaped, the coefficient of the variable containing the squared environmental performance values was statistically tested with the Wald test. The coefficient value of 7.27 was statistically significant at the 0.01 level (Wald $=10.71, p<0.001$ ). Thus, the data support Hypothesis 1. A diagram of the U-shaped relationship between environmental performance and voluntary disclosure is presented in Figure 2. A number of points should be noted regarding the $U$-shaped relationship. First, the $y$-axis represents the $\log$ of the odds ratio of voluntarily disclosing environmental information. Second, the 
TABLE II

Results of ordinal regression models ${ }^{\mathrm{a}}$

\begin{tabular}{|c|c|c|c|c|}
\hline & \multicolumn{2}{|l|}{ Model $1^{\mathrm{b}, \mathrm{c}}$} & \multicolumn{2}{|l|}{ Model $2^{\mathrm{d}, \mathrm{e}}$} \\
\hline & Coefficient estimate (SE) & Wald test & Coefficient estimate (SE) & Wald test \\
\hline \multicolumn{5}{|l|}{ Threshold } \\
\hline Moderate disclosure & $-1.89(1.02)$ & 3.43 & $-1.65(1.04)$ & 2.53 \\
\hline High disclosure & $-0.71(1.02)$ & 0.48 & $-0.46(1.03)$ & 0.20 \\
\hline \multicolumn{5}{|l|}{ Location } \\
\hline Size & $-0.01(0.08)$ & 0.02 & $-0.01(0.08)$ & 0.01 \\
\hline Financial performance & $-0.20(0.14)$ & 2.12 & $-0.21(0.14)$ & 2.29 \\
\hline Visibility & $0.62(0.17)$ & $12.90 \star \star \star$ & $0.72(0.19)$ & $14.88^{\star \star \star}$ \\
\hline Environmental performance & $3.03(0.86)$ & $12.49 \star \star \star$ & $3.38(1.74)$ & 3.77 \\
\hline $\begin{array}{l}\text { Environmental performance }{ }^{2} \\
\text { EnperXvis }\end{array}$ & $\begin{array}{l}7.27(2.22) \\
(0.91)\end{array}$ & $10.71 \star \star \star$ & $\begin{array}{l}13.02(4.92) \\
(0.92)\end{array}$ & $7.01 \star \star$ \\
\hline EnperXvis $^{2}$ & (10.0 & & $\begin{array}{l}-0.15(1.26) \\
-5.29(3.57)\end{array}$ & $\begin{array}{l}0.02 \\
2.20\end{array}$ \\
\hline \multicolumn{5}{|l|}{ Industry } \\
\hline Consumer discretionary & $-1.97(0.58)$ & $11.67 \star \star \star$ & $-1.87(0.58)$ & $10.33 \star \star \star$ \\
\hline Consumer staples & $-1.54(0.63)$ & $6.01 \star \star$ & $-1.44(0.64)$ & $5.15^{\star}$ \\
\hline Energy & $-0.96(0.62)$ & 2.41 & $-0.85(0.63)$ & 1.82 \\
\hline Financials & $-1.85(0.58)$ & $10.03 \star \star$ & $-1.75(0.59)$ & $8.84 \star \star$ \\
\hline Healthcare & $-1.45(0.61)$ & $5.66^{\star \star}$ & $-1.34(0.62)$ & $4.76^{\star}$ \\
\hline Industrials & $-1.67(0.58)$ & $8.30 \star \star$ & $-1.57(0.59)$ & $7.11 \star \star$ \\
\hline Information technology & $-2.47(0.61)$ & $16.23 \star \star \star$ & $-2.35(0.62)$ & $14.39 \star \star \star$ \\
\hline Materials & $-0.44(0.67)$ & 0.44 & $-0.33(0.68)$ & 0.25 \\
\hline Telecom services & -2.23 & $5.99 \star \star$ & -2.14 & $5.43^{\star}$ \\
\hline
\end{tabular}

$\star_{p}<0.05,{ }^{\star \star} p<0.01,{ }^{\star \star \star} p<0.001$

${ }^{a}$ Link function: Logit.

b-2 log-likelihood values for the Null Model and the General Model were 768.02 and 705.99, respectively. The difference between these two values was statistically significant $\left(\chi^{2}(14)=62.03, p<0.001\right)$.

${ }^{c}$ Parallel test for Model 1: $-2 \log$-likelihood values for the Null Model (705.99) and the General Model (694.91); the difference between these two values was statistically significant $\left(\chi^{2}(14)=11.09, p=0.68\right)$.

d-2 log-likelihood values for the Null Model and the General Model were 768.02 and 703.93, respectively. The difference between these two values was statistically significant $\left(\chi^{2}(16)=64.09, p<0.001\right)$.

${ }^{\mathrm{e}}$ Parallel test for Model 1: $-2 \log$-likelihood values for the Null Model (703.93) and the General Model (692.17); the difference between these two values was statistically significant $\left(\chi^{2}(16)=11.09, p=0.76\right)$.

\section{TABLE III}

Descriptive statistics and correlations for the continuous independent variables

\begin{tabular}{lrrrrr}
\hline & Mean & SD & 1 & 2 & 3 \\
\hline 1. Financial performance & 1.91 & 0.81 & & & \\
2. Size & 8.91 & 1.39 & $-0.32 \star \star$ & & \\
3. Environmental performance & -0.02 & 0.17 & 0.09 & -0.05 & \\
4. Visibility & 1.00 & 0.63 & -0.09 & 0.04 & 0.05 \\
\hline
\end{tabular}

$\star \star$ Correlation is significant at the 0.01 level (2-tailed). 


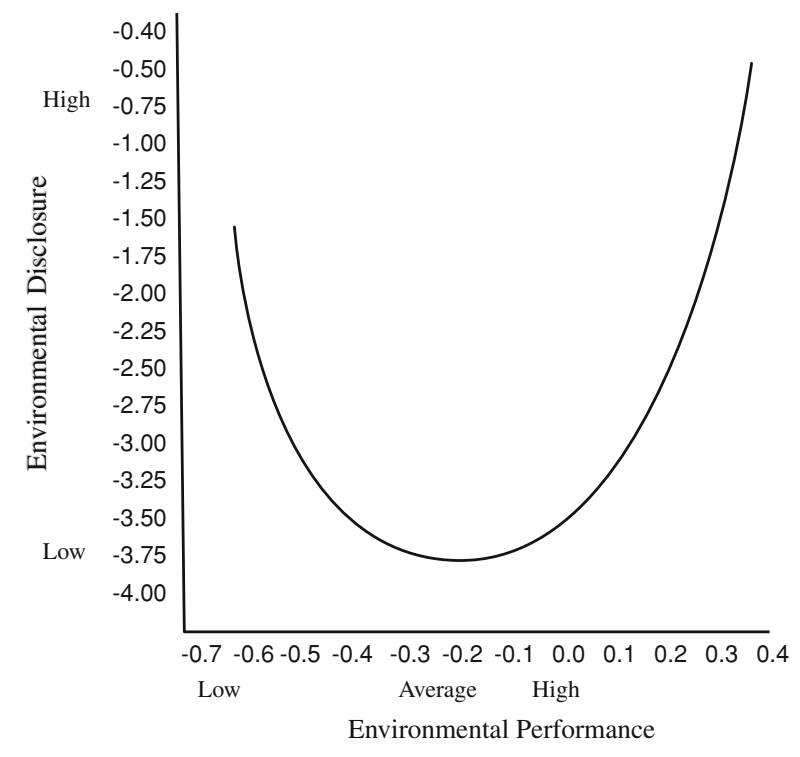

Figure 2. U-shaped relationship between environmental performance and environmental disclosure.

curve was estimated for the CERES $=1$ threshold value, the consumer discretionary industry and the mean values for size, performance, and visibility.

A review of the diagram in Figure 2 reveals that as environmental performance increases for values between -0.70 and -0.21 , the odds ratio values (i.e., the likelihood of environmental disclosure) decrease. However, as environmental performance increase for values above -0.21 , the odds ratio values increase.

\section{Test of Hypothesis 2 with Model 2}

In order for the data to support Hypothesis 2, that is, the U-shaped relationship between environmental performance and voluntary environmental was modified by visibility, either of the coefficients for the enperXvis $(-0.15)$ and enperXvis ${ }^{2}(-5.29)$ variables must be statistically significant. Since neither the Wald test for the enperXvis coefficient (Wald = $0.12, p=0.90)$ nor the Wald test for the enperXvis ${ }^{2}$ coefficient (Wald $=2.20, p=0.14$ ) was significant, Hypothesis 2 was not supported by the data. Thus, the U-shaped relationship between environmental performance and voluntary environmental was not modified by visibility.

Because the visibility variable did not interact with the environmental performance variable, we conducted tests to determine if the main effect of visibility was significant. The positive coefficient for the visibility variable $(0.73)$ in Model 2 was statistically significant (Wald $=3.39, p<0.001$ ). Thus, as a firm's visibility score increases the firm is more likely to voluntarily disclose environmental information.

\section{Discussion}

\section{Overview and contributions}

There was a curvilinear relationship between environmental performance and voluntary environmental disclosure, indicating that firms at the high and low ends of the environmental performance spectrum were more likely to voluntary disclose information than firms in the middle of that spectrum. Visibility was positively related to environmental disclosure, but does not moderate the impact of environmental performance on environmental disclosure. Apparently, the fact that a firm is visible motivates disclosure regardless of whether firm performance is favorable or unfavorable.

It may be that firms with unlike degrees of environmental performance perceive environmental disclosure differently. This difference can be explained by the adaptive strategies proposed by Miles and Snow (1978). Leading environmental performers may disclose more as they seek to enhance legitimacy and reputation through their environmental performance. Environmental pacesetters or frontrunners that are perceived as highly legitimate have often achieved this status through increased exposure (Pollock and Rindova, 2003). Firms with average environmental performance, however, may be more likely to be analyzers seeking moderate, steady environmental performance, and limited opportunities for first mover advantage enjoyed by leading firms. Analyzers are rarely first to market with new products or services. Instead, they try to simultaneously minimize risk and maximize profits by following or imitating the proven successes of prospectors. Because the firms with low environmental performance are not seeking opportunities for environmental performance in a proactive manner, they are left to react to concerns about legitimacy rather than execute a consistent environmental performance strategy. 
Fombrun et al. (2000) characterize different approaches to CSP in terms of opportunity platforms and safety nets. Firms that were rated highly for environmental strengths utilized environmental disclosure as an opportunity platform, while those that exhibited more environmental weaknesses used disclosure as a safety net against threats to legitimacy. As firms' environmental performance deteriorates, it becomes more necessary to provide reasons for the poor performance and assurance of commitment to the environment (Bansal and Clelland, 2004), and as performance improves it becomes more valuable as a strategic asset. There is an emerging stream of research examining how companies use CSR reporting to highlight their commitment to corporate social responsibility (e.g., Brammer and Pavelin, 2004; Hooghiemstra, 2000). Institutional pressure and increased visibility appear to be key reasons for attempts to alter public perception about the legitimacy of the firms through voluntary disclosure. Firms with neither low nor high environmental performance were less likely to perceive the need to act for reasons of strategic opportunity or safety.

By focusing on reconciling the legitimacy and voluntary disclosure approaches to environmental disclosure, our analysis opens up new avenues for research. First, it contributes toward clarification of the different outcomes proposed by legitimacy theory and voluntary disclosure explanations for environmental performance-environmental disclosure relation. Second, it highlights the role of visibility in the amount of disclosure firms are willing to make. Third, the study provides some new methodological approaches. Using the KLD and Ceres databases enabled a very broad and representative sample, which has been lacking in a number of previous studies due to the limitations of acquiring environmental data. The measure of environmental performance included proactive types of planning and reporting in addition to outcome measures that have tended to result in a negative relationship between performance and disclosure.

\section{Implications for research and practice}

Although the study sheds light on a variety of issues surrounding environmental performance and environmental disclosure and raises the issue of visibility (at least in large, American, publicly held firms), it raises other issues about the role of visibility and the behavior of average performing firms versus those at the ends of the performance spectrum. As Clarkson et al. (2008) have alluded, future research should examine poor and strong performers' use of more strategic disclosure techniques (e.g., partial or full disclosure) to capture a greater variation of type and form of environmental responses. Neither the legitimacy nor voluntary disclosure approaches focus on firms with average environmental performance ratings. Given that most firms are likely to exhibit average environmental performance, future research might focus on firms with moderate levels of environmental performance as well.

It would also be beneficial to test for nonlinear relationships among different industries with respect to environmental performance and environmental disclosure. As our results show, there are considerable disclosure differences among industries that have a high impact on the environment and those that have a low impact on the environment. While this finding is consistent with previous research (Kolk, 2003), future research could focus on firms within a single high-impact industry to tease out within-sector differences. Likewise, a low-impact industry, such as banking, could be examined to see why some firms within that industry are proactive in terms of environmental disclosures while others are not. More research is needed to address these important questions.

In view of our findings, managers of firms with inconspicuous environmental performance may indeed have more discretion in their activities than their more conspicuous peers. For stakeholder groups, the implication is very clear; managers respond to sunlight and exposure similar to the Ceres environmental "watch" list is likely to be effective. According to signaling theory (Spence, 1973), corporations with superior information transparency signal better corporate governance. Hence, even those who do not choose to provide disclosure are, by default, giving an indication of how their firms view disclosure.

\section{Study limitations and conclusion}

The limitations of this study provide avenues for further research. First, the results of the study might 
be enriched by a finer grained analysis of visibility. In this study, we made no distinction between articles that report on environment or sustainability and those that may be touting a new product launch. While visibility need not be directly related to environmental issues, a careful analysis that provides the tenor of visibility and press coverage, though a daunting and time consuming task, might lead to a better understanding of the role of visibility coverage associated with firms' patterns of disclosure. Second, because we have no absolute measure of environmental performance, it is possible that we have a sample or sample year in which most firms performed well or poorly. Finally, a longitudinal approach to assess environmental performance might be helpful in addressing this shortcoming. By shedding a bit more light on the nature of the interface between environmental performance and environmental disclosure, we hope to assist the efforts of firms in providing disclosure in a financially and socially responsible manner, and stakeholders in efforts to receive the information they need to protect their interests.

\section{Notes}

1 The TRI is a publicly available Environmental Protection Agency database that contains information on toxic chemical releases and waste management activities reported annually by certain industries as well as federal facilities.

2 Banking \& Financial - Wells Fargo; Electric Power - TXU, Dominion Resources, and Allegheny Energy; Coal - Massey Energy and Consol. Energy Insurance ACE; Oil \& Gas - ExxonMobil and ConocoPhillips; and Retail - Bed Bath \& Beyond.

3 As of December 31, 2005.

4 Ceres makes the firm responses available to its members and, with the firm's permission, publishes its report on its web site for general access.

5 For example, the company attached its corporate sustainability report.

6 The number of items used to rate strengths and weaknesses differed, which precluded simply subtracting total weakness scores from total strength scores to obtain a composite score.

7 In order to be counted as a "mention" the firm had to be included in the article title and first paragraph.

8 Log of total assets was used because the distribution was skewed by a few very large observations.

\section{Appendix: KLD environmental performance rating criteria}

\section{Strengths}

1. Beneficial products and services. The company derives substantial revenues from innovative remediation products, environmental services, or products that promote the efficient use of energy, or it has developed innovative products with environmental benefits.

2. Pollution prevention. The company has notably strong pollution prevention programs including both emissions reductions and toxic-use reduction programs.

3. Recycling. The company either is a substantial user of recycled materials as raw materials in its manufacturing processes or a major factor in the recycling industry.

4. Clean energy. The company has taken significant measures to reduce its impact on climate change and air pollution through use of renewable energy and clean fuels or through energy efficiency. The company has demonstrated a commitment to promoting climatefriendly policies and practices outside its own operations.

5. Communications. The company is a signatory to the Ceres Principles, publishes a notably substantive environmental report, or has notably effective internal communications systems in place for environmental best practices.

6. Property, plant, and equipment. The company maintains its property, plant, and equipment with above-average environmental performance for its industry. KLD has not assigned strengths for this issue since 1995.

7. Management systems. The company has demonstrated a superior commitment to management systems through ISO 14001 certification and other voluntary programs. This strength was first awarded in 2006.

8. Other strength. The company has demonstrated a superior commitment to management systems, voluntary programs, or other environmentally proactive activities. 
Concerns

1. Hazardous waste. The company's liabilities for hazardous waste sites exceed $\$ 50$ million, or the company has recently paid substantial fines or civil penalties for waste management violations.

2. Regulatory problems. The company has recently paid substantial fines or civil penalties for violations of air, water, or other environmental regulations, or it has a pattern of regulatory controversies under the Clean Air Act, Clean Water Act, or other major environmental regulations.

3. Ozone depleting chemicals. The company is among the top manufacturers of ozone depleting chemicals such as HCFCs, methyl chloroform, methylene chloride, or bromines.

4. Substantial emissions. The company's legal emissions of toxic chemicals (as defined by and reported to the EPA) from individual plants into the air and water are among the highest of the companies followed by KLD.

5. Agricultural chemicals. The company is a substantial producer of agricultural chemicals, i.e., pesticides or chemical fertilizers.

6. Climate change. The company derives substantial revenues from the sale of coal or oil and its derivative fuel products, or the company derives substantial revenues indirectly from the combustion of coal or oil and its derivative fuel products. Such companies include electric utilities, transportation companies with fleets of vehicles, auto and truck manufacturers, and other transportation equipment companies.

7. Other concern. The company has been involved in an environmental controversy that is not covered by other KLD ratings.

\section{References}

Adams, C. A.: 2004, 'The Ethical, Social and Environmental Reporting-Performance Portrayal Gap', Accounting, Auditing \& Accountability Journal 17(5), 731-757.

Al-Tuwaijri, S. A., T. E. Christensen and K. E. Hughes: 2004, 'The Relations Among Environmental Disclosure, Environmental Performance, and Economic
Performance: A Simultaneous Equations Approach', Accounting, Organizations \& Society 29(5/6), 447-465.

Bansal, P. and I. Clelland: 2004, 'Talking Trash: Legitimacy, Impression Management, and Unsystematic Risk in the Context of the Natural Environment', Academy of Management Journal 47(1), 93-103.

Bansal, P. and G. Kistruck: 2006, 'Seeing is (not) Believing: Managing the Impressions of the Firm' and Commitment to the Natural Environment', Journal of Business Ethics 67(2), 165-180.

Bansal, P. and K. Roth: 2000, 'Why Companies Go Green: A Model of Ecological Responsiveness', Academy of Management Journal 43(4), 717-736.

Brammer, S. and S. Pavelin: 2004, 'Voluntary Social Disclosures by Large UK Companies', Business Ethics: A European Review 13(2/3), 86-99.

Brown, N. and C. Deegan: 1998, 'The Public Disclosure of Environmental Performance Information - A Dual Test of Media Agenda Setting Theory and Legitimacy Theory', Accounting \& Business Research 29(1), 21-41.

Bushman, R. M., J. D. Piotroski and A. J. Smith: 2004, 'What Determines Corporate Transparency?', Journal of Accounting Research 42(2), 207-252.

Ceres: 2007a, January 31, SEP 500 Companies Faulted For Poor Climate Disclosure. Downloaded from the World Wide Web on February 26, 2007, http://www.ceres. org/news/news_item.php?nid=264.

Ceres: 2007b, TXU, Exxon Mobil Among 10 'Climate Watch' Companies Targeted by Investors. Retrieved May 22, 2008, from http://news-ceres.blogspot.com/ 2007/02/txu-exxon-mobil-among-10-climate-watch. html.

Ceres: 2007c, Climate Risk Disclosure and the SEP 500. Ceres. Downloaded from the World Wide Web on February 26, 2007, http://www.ceres.org/Document. Doc?id=473. Retrieved June 15, 2009.

Chen, C. C. and J. R. Meindl: 1991, 'The Construction of Leadership Images in the Popular Press: The Case of Donald Burr and People Express', Administrative Science Quarterly 36(4), 21-55.

Cho, C., D. Patten and R. Roberts: 2006, 'Corporate Political Strategy: An Examination of the Relation between Political Expenditures, Environmental Performance, and Environmental Disclosure', Journal of Business Ethics 67(2), 139-154.

Clarkson, P. M., Y. Li, G. D. Richardson and F. P. Vasvari: 2008, 'Revisiting the Relation Between Environmental Performance and Environmental Disclosure: An Empirical Analysis', Accounting, Organizations \& Society 33(4/5), 303-327.

Dawkins, C. E.: 2002, 'Corporate Welfare, Corporate Citizenship, and the Question of Accountability', Business \& Society 41(3), 269. 
Dawkins, C. E.: 2005, 'First to Market: Issue Management Pacesetters and the Pharmaceutical Industry Response to AIDS in Africa', Business \& Society 44(3), 244-282.

Deegan, C. and B. Gordon: 1996, 'A Study of the Environmental Disclosure Practices of Australian Corporations', Accounting \& Business Research 26(3), 187-199.

Deegan, C., M. Rankin and P. Voght: 2000, 'Firms' Disclosure Reactions to Major Social Incidents: Australian Evidence', Accounting Forum 24(1), 101-130.

Dutton, J. E. and S. J. Ashford: 1993, 'Selling Issues to Top Management', Academy of Management Review 18(3), 397-428.

Dye, R. A.: 2001, 'An Evaluation of 'Essays on Disclosure' and the Disclosure Literature in Accounting', Journal of Accounting and Economics 32, 181-235.

Erfle, S., H. McMillan and B. Grofman: 1990, 'Regulation via Threats: Politics, Media Coverage, and Oil Pricing Decisions', Public Opinion Quarterly 54(1), 48-49.

Fombrun, C. J.: 1996, Reputation: Realizing Value from the Corporate Image (Harvard Business School Press, Boston).

Fombrun, C., N. Gardberg and M. L. Barnet: 2000, 'Opportunity Platforms and Safety Nets: Corporate Citizenship and Reputational Risk', Business and Society Review 105, 85-106.

Gans, H. J.: 1979, Deciding What's News (Pantheon Books).

Godfrey, P. C.: 2005, 'The Relationship Between Corporate Philanthropy and Shareholder Wealth: A Risk Management Perspective', Academy of Management Review 30, 777-798.

Graves, S. B. and S. A. Waddock: 1994, 'Institutional Owners and Corporate Social Performance', Academy of Management Journal 37(4), 1034.

Gray, R., R. Kouhy and S. Lavers: 1995, 'Corporate Social and Environmental Reporting: A Review of the Literature and a Longitudinal Study of UK Disclosure', Accounting, Auditing \& Accountability Journal 8(2), 47-77.

Hooghiemstra, R.: 2000, 'Corporate Communication and Impression Management - New Perspectives Why Companies Engage in Corporate Social Reporting', Journal of Business Ethics 27(1/2), 55-68.

Hughes, S. B., A. Anderson and S. Golden: 2001, 'Corporate Environmental Disclosures: Are They Useful in Determining Environmental Performance?', Journal of Accounting \& Public Policy 20(3), 217-240.

Johnson, R. A. and D. W. Greening: 1999, 'The Effects of Corporate Governance and Institutional Ownership Types of Corporate Social Performance', Academy of Management Journal 42(5), 564-576.
Johnston, P.: 1994, Success While Others Fail: Social Union Movementism and the Public Workplace (ILR Press, Ithaca, NY).

KLD Analytics (2007). Research Methodology. http:// www.kld.com/research/methodology.html; July 29.

Klein, N.: 2000, No Logo: Taking Aim at the Brand Bullies (Picador, New York).

Kolk, A.: 2003, 'Trends in Sustainability Reporting by the Fortune Global 250', Business Strategy and the Environment 12(5), 279-291.

Lindblom, C. K.: 1994, The Implications of Organizational Legitimacy for Corporate Social Performance and Disclosure. Critical Perspectives on Accounting Conference, New York.

Mackey, A., T. B. Mackey and J. B. Barney: 2007, 'Corporate Social Responsibility and Firm Performance: Investor Preferences and Corporate Strategies', Academy of Management Review 32(3), 817-835.

Mahon, F. A. and S. A. Waddock: 1992, 'Strategic Issues Management: An Integration of Issue Life Cycle Perspectives', Business and Society 31(1), 19-32.

Maignan, I. and O. C. Ferrell: 2001, 'Antecedents and Benefits of Corporate Citizenship: An Investigation of French Businesses', Journal of Business Research 51(1), 3751.

McWilliams, A. and D. Siegel: 2001, 'Corporate Social Responsibility: A Theory of the Firm Perspective', Academy of Management Review 26(1), 117-127.

Meznar, M. B., J. H. Johnson Jr. and P. J. Mizzi: 2006, 'No News is Good News? Press Coverage and Corporate Public Affairs Management', Journal of Public Affairs (14723891) 6(1), 58-68.

Meznar, M. B. and D. Nigh: 1995, 'Buffer or Bridge? Environmental and Organizational Determinants of Public Affairs Activities in American Firms', Academy of Management Journal 38(4), 975-996.

Miles, R. E. and C. C. Snow: 1978, Organizational Strategy, Structure, and Process (McGraw-Hill, New York).

Oliver, C.: 1991, 'Strategic Responses to Institutional Processes', Academy of Management Review 16(1), 145-179.

Patten, D. M.: 2002, 'The Relation Between Environmental Performance and Environmental Disclosure: A Research Note', Accounting, Organizations \& Society 27(8), 763-773.

Pfeffer, J. and G. R. Salancik: 1978, The External Control of Organizations: A Resource Dependency Perspective (Harper \& row, New York).

Pollock, T. G. and V. P. Rindova: 2003, 'Media Legitimation Effects in the Market for Initial Public Offerings', Academy of Management Journal 46(5), 631642.

Porter, M. E. and C. van der Linde: 1995, 'Toward a New Conception of the Environment-Competitive- 
ness Relationship', Journal of Economic Perspectives 9(4), 97-118.

Roberts, R. W.: 1992, 'Determinants of Corporate Social Responsibility Disclosure: An Application of Stakeholder Theory', Accounting, Organizations \& Society 17(6), 595-612.

Russo, M. V. and P. A. Fouts: 1997, 'A Resource-Based Perspective on Corporate Environmental Performance and Profitability', Academy of Management Journal 40(3), 534-559.

Spence, M.: 1973, 'Job Market Signaling', Quarterly Journal of Economics 87(3), 355-374.

Verrecchia, R. E.: 1983, 'Discretionary Disclosure', Journal of Accounting \& Economics 5(3), 179-194.

Waddock, S.: 2003, 'Myths and Realities of Social Investing', Organization \& Environment 16(3), 369.

Waddock, S. A. and S. B. Graves: 1997, 'The Corporate Social Performance-Financial Performance Link', Strategic Management Journal 18(4), 303-319.

Wartick, S. L. and P. L. Cochran: 1985, 'The Evolution of the Corporate Social Performance Model', Academy of Management Review 4, 758-769.
Wartick, S. L. and J. F. Mahon: 1994, 'Toward a Substantive Definition of the Corporate Issue Construct', Business \& Society 33(30), 293-312.

Wiseman, J.: 1982, 'An Evaluation of Environmental Disclosures made in Corporate Annual Reports', Accounting, Organizations \& Society 7(1), 53-63.

Cedric E. Dawkins Management and Human Resources, California State Polytechnic University - Pomona, Pomona, CA, U.S.A. E-mail:cedawkins@csupomona.edu

John W. Fraas Business Administration, Ashland University, Ashland, CA, U.S.A. E-mail:jfraas@ashland.edu 